\title{
Curriculum Change and Self-Governing Agreements: A Yukon First Nation Case Study ${ }^{1}$
}

\author{
Brian Ellis Lewthwaite \\ James Cook University \\ Australia \\ Thomas Owen \\ Auckland University of Technology \\ New Zealand \\ Ashley Doiron \\ Tr'ondëk Hwëch'in First Nation, Yukon Territory \\ Canada
}

ABSTRACT: Recent developments in Canada's Yukon Territory draw attention to how political changes have potential for accelerating practices in education that are responsive to Indigenous Peoples' cultural knowledge systems and practices. In this study, through the use of case study methodology, an account of the changes that have occurred in one First Nation are presented. Further, the study seeks to identify the processes influencing the development. Finally, tensions at the classroom, school, and community levels arising from these changes and anticipated changes are described.

\section{KEYWORDS: First Nations, curriculum, self-governance, Canada Yukon} Territory, Indigenous People

\author{
Context of the Study \\ Methodology \\ Results \\ Discussion and Implications \\ Conclusion \\ Note \\ References
}

Recent developments in Canada's Yukon Territory draw attention to how political changes have potential for accelerating practices in education that are responsive to Indigenous Peoples' cultural knowledge systems and practices. In contrast to other provincial jurisdictions across southern Canada, treaties between the Government of Canada and the Yukon's 12 First Nation groups were historically never negotiated in the Yukon. Over the past three decades the governments of both Canada and the Yukon have moved towards actualizing 
policy developments with Yukon First Nations (YFNs), called Self-Government Agreements (SGAs) The journey towards this end is well documented in Canadian literature (for example, Fallon \& Paquette, 2012). SGAs, which in the Canadian context are unique to the Yukon, are complex and wide-ranging, and include financial compensation, land, harvesting rights, heritage resources and operative governance structures in areas such as education and justice.

Within each Self-Governing First Nation (SGFN), considerable attention is given to inclusion of principles that acknowledge the traditional decision-making institutions of YFNs and ensure that these are reinstated in institutional practices within contemporary forms of government (Tr'ondëk Hwëch'in, 1998). Because of this imperative, with the establishment of SGFNs, each YFN with the required cooperation of Yukon Education (YE) (1990) faces the challenge of reversing assimilation and, by such, regaining a sense of identity especially within the processes that influence practice (Smith, 1997), Typical of most Aboriginal peoples, YFNs have participated in a school system that has been drawn from the dominant culture (Foster \& Goddard, 2001; Lewthwaite, Owen, Doiron, McMillan, \& Renaud, 2013; Lewthwaite, Owen, Doiron, Renaud, \& McMillan, 2014). Because of this, school processes and practices have both intentionally and unintentionally denied the inclusion of those aspects of YFN culture that have value and are important to YFN children (Battiste \& Henderson, 2000).

Within this paper we seek to investigate the processes at work that seek to alter the curriculum experience provided for citizens within a Yukon First Nation with the advent of self-governing agreements. Specifically we ask: What processes have influenced, negatively or positively, curriculum development that is the broad learning experience provided for students? What tensions exist as a result of a change in governance agreements in regards to curriculum development?

\section{Context of the Study: Self-governance for Tr'ondëk Hwëch'in}

For Tr'ondëk Hwëch'in First Nation (THFN) in Dawson City, Yukon, the establishment of their specific SGA in 1998 has brought with it significant opportunity for educational change. First Nation citizens in Dawson comprise $39 \%$ of the total community population of 2002 (Yukon Bureau of Statistics, 2014), consistent with the $37 \%$ of the total local kindergarten through grade 12 in the lone community school population of 224. Negotiations between THFN and the governments of both Canada and the Yukon resulted in the inclusion of a general jurisdictional governance statement within their SGA, article 17.1, which provides for the "assumption of responsibility by the Tr'ondëk Hwëch'in (TH) for the management, administration and delivery of any program or service within the jurisdiction of Tr'ondëk Hwëch'in" (Tr'ondëk Hwëch'in, 2010, p. 32). Within the broader scope of program delivery in general, as outlined in article 17.1, is specific reference to education in sub-article 17.7 , which specifically outlines the provision for education. Notwithstanding that the SGA provides potential for $\mathrm{TH}$ 
to work towards autonomous control of education, which could be entirely independent of Yukon Education, the SGA also makes explicit the provisions to be enacted if a shared delivery of education is decided upon by the First Nation.

In relation to education, upon the request of the Tr'ondëk Hwëch'in, the Tr'ondëk Hwëch'in and the Yukon shall during the term of a selfgovernment financial transfer agreement, negotiate the division and sharing of responsibility for the design, delivery and administration of programs delivered within the Traditional Territory relating to [amongst other things] kindergarten through grade 12 curriculum. (Tr'ondëk Hwëch'in, 1998, p. 33).

The agreement draws attention to a variety of school operation aspects that broadly influence what can be regarded as the school's 'curriculum.' As Ornstein and Hunkins (2013) endorse, curriculum is defined more broadly as the totality of experiences provided for learners, drawing into consideration not only what is learned, but also how it is learned, and from whom and, possibly most significantly at an epistemological level, why is it learned and for what purpose. It is this description of curriculum that informs this paper.

Central to the enactment of this curriculum possibility is understanding the structure of self-governance in education in Dawson and the potential tensions that can ensue in curriculum development as a result of this structure. The assumption of responsibility within the self-governing agreement is granted to the First Nation to decide in negotiation with Yukon Education on how these SGA imperatives are operationalized. The TH SGA Implementation Director states:

[There was provision for TH's] own self-managed education system, its own separate education system in Dawson, but this was definitely what the $\mathrm{TH}$ citizens did not want. The $\mathrm{TH}$ see themselves as part of an integrated community, they don't want a separate education system. They wanted a united system, a merged system, essentially a marriage between the $\mathrm{TH}$, the Government of Yukon, where each would be equal partners and in essence enter into a co-management system or even call it co-governance when it comes to education (personal communication, September 21, 2014).

Although the SGA provides TH with the policy space to create selfcontained FN education systems, TH have instead chosen to use this authority to create a merged integrated system. Fallon and Paquette (2012) state:

Within this [SGA] co-governance model, the province or territory retains ultimate authority over laws, regulations, and policies setting forth education standards and criteria for academic success. By so doing, this structure represents a form of neo-colonialism rather than it does [a structure for facilitating] decolonization [italics authors]. (p. 12)

For TH, the SGA implementation has seen the establishment of the THFN Educational Council headed by an Education Manager who co-directs curriculum development, in its broadest form, with the school principal and the school's 
teachers. This co-governance system becomes, quite likely, problematic because, as commonly identified in the literature, school operations and education in general within colonized Indigenous contexts, largely marginalize and subordinate any epistemological aspirations for education that might be sought by Indigenous communities (Battiste \& Henderson, 2000). McKinley (2000) argues that curriculum, the totality of experience provided for learners, is largely an expression of the dominant culture because the intention of curriculum is not adequately grounded in the priorities and epistemologies of Indigenous communities and, as identified, typically remains unchallenged and perpetuates, even when provision is made for self-governance (Wood \& Lewthwaite, 2008). The development of SGAs quite obviously draws attention to the potential and likely incongruence between the intentions and aspirations of the dominant nation-state and the emergent First Nation. It is within this space that tensions between decolonization and neocolonialism are likely to be evidenced.

It is not surprising that the critique of self-governance agreements in Canada draws attention to the tensions and dilemmas likely to be experienced in curriculum development and enactment in such contexts because, as Fallon and Paquette (2012) assert that self-governance is but a form of governance likely disguised as "neo-colonialism": a system in which "colonial power can still unwittingly undermine or negate Indigenous educational patterns, many of which are linked to cultural norms and values" (Nguyen, Elliott, Terlouw, \& Pilot, 2009, p. 111). Thus, in this paper we explore what contributes to change towards First Nation aspirations being realised in curriculum, especially when hegemonic influence (Gramsci, 1971) is likely deeply entrenched within the operation of education broadly and in schools and classrooms specifically.

\section{Methodology}

The method used in this research inquiry is the case study. This section provides an explanation of how the case study method was used and Urie Bronfenbrenner's (2005) bio-ecological theory frames the study.

\section{Method}

The case study method was utilized in this study. The study endeavours to understand and explain a phenomenon: the processes influencing educational development that responds to the aspirations of the assertions of a SGA, in this study's case, the Tr'ondëk Hwëch'in SGA (1998). The study strives towards a holistic understanding of cultural systems of action influencing curriculum development within a social system, a school community (Sjoberg, Williams, Vaughan, \& Sjoberg, 1991). The unit of analysis in this case study is the dominant players in the school community: the TH citizens including its Elders; Chief and Council; administrators including Education Manager; Heritage 
Department members and Community Education Liaison Coordinators (CELCs); Yukon Education employees including superintendent, principal and teachers, the latter of which includes both TH and non-TH citizens; and, finally, school community members including $\mathrm{TH}$ and non-TH students and parents. Drawing upon multiple sources of information, the researchers sought to make sense of the respondents' personal stories pertaining to curriculum development and the ways in which these stories intersect in order to collaboratively construct a meaningful reality (Creswell, 2012).

\section{Theoretical Position}

Urie Bronfenbrenner's (2005) bio-ecological theory, a theory that has only recently been applied to community-based educational development (see, for example, Lewthwaite \& McMillan, 2007) was used as the primary theoretical frame to identify and understand the processes influencing the curriculum development in response to the SGA aspirations. Within his bio-ecological theory, development is defined as the phenomenon of continuity and change in the characteristics of human beings both as individuals and as groups. Of importance to this study, Bronfenbrenner described development as the sustained, progressively more complex interaction with and activity in the immediate environment. These descriptions of development are central to this study. If a school community in its curriculum enactment is indeed developing in accordance with the SGA intent, there should be evidence of progressively more complex interaction and activity, both at the individual and group level, in the aspects that provide for the realisation of the aspired broader curriculum experience. This experience would be consistent with both its citizens' and the documented SGA intent.

For Bronfenbrenner (1979), the ecological environment, unique to each individual's situation, is seen as a series of nested and interconnected structures, ranging from the individual to the macrosystem. The macrosystem includes the much broader cultural and political systems in which the individual or group is located. The innermost structure includes the individuals central to the process under consideration. Within this study's case, the primary players at the school level are charged with enacting curriculum: for example, teachers, students, Elders, CLECs, and, less directly, principal, parents (both both TH and non-TH), and the TH Heritage Department and Education Manager. Bronfenbrenner suggests that individuals possess developmentally instigative characteristics that invite, inhibit, or prevent engagement in sustained, progressively more complex interaction with and activity in the immediate environment (p. 97). Within the context of this study, as inferred by Fullan (1993), a teacher's receptivity to curricular adjustment in line with TH curriculum aspiration and her competence in enacting such is likely to be a developmentally instigative personal attribute that influences curriculum development in accordance with THFN aspiration. Similarly, Bronfenbrenner suggested that the most proximal and significant sphere or setting is the individual's microsystem. The microsystem includes the pattern of activities, roles, and interpersonal relations experienced by the 
developing person in a given face-to-face setting with particular material and physical features and containing other persons with distinctive characteristics, personalities, and systems of belief (Bronfenbrenner, p. 148). Within the context of this study, which focuses on the broader curriculum experience provided for students, the strengths of the relationships, collaborative capabilities, and the resourcing and leadership provided, as evidenced in other educational contexts (Lewthwaite, McMillan, Renaud, Hainnu, \& MacDonald, 2010) are likely critical aspects influencing such development. Bronfenbrenner's model emphasizes, especially, proximal processes usually within an individual's microsystem: those patterns of activation that drive or thwart stability and change. In the context of this study, this construct has obvious applicability. It becomes important for the key players to be actively involved in a pattern of activity that mobilizes and sustains attention, develops knowledge, and encourages the individual, and group, to attain slightly higher levels of functioning (Bronfenbrenner, 2005).

Supporting Bronfenbrenner's (2005) theoretical frame is a further paradigm, critical pedagogy, which is likely essential to understanding processes that might drive or thwart change post-SGA introduction. Critical pedagogy is defined as an educational movement to help develop consciousness of freedom, recognize authoritarian tendencies, and connect this knowledge as a foundation for taking constructive action (Giroux, 2010). The primary intent of the YFN SGAs is a response to a critical awareness of the injustice of existing social orders, including education, that have historically disenfranchised YFNs and this study's case, the curriculum influencing student learning. In response, critical theory, similar to the underlying premise of the SGAs, re-examines and ultimately assists in the re-construction of practices in order to work towards a social order based upon a reconceptualization of what can and should be. Most evident within critical theory writing is the emphasis on the idea of a growing "consciousness" of one's condition amongst individuals, a 'conscientisation' Freire $(1970,1998)$ refers to as the first step to constructive action in an educational practice of consequence for students.

\section{Data Collection and Analysis}

This study focused on a three-stage data collection process, although aspects of the first two stages have been reported on earlier writings (Lewthwaite et al., 2013; Lewthwaite, Owen, Doiron, Renaud, \& McMillan, 2014). In the first stage of the research, conducted in 2008 and 2009, the first researcher engaged with TH Elders, Chief and Council, Education Manager, teachers, parents, and high school students to elicit their aspirations for education, especially in terms of the broader curriculum provided for students. Special attention was given to not only the what of curriculum, but also the how and why? Emanating from the discussion was an aspiration that the educational experiences provided should be reflected not only in the management and operation processes of the school but also in the curricula and programs implemented and pedagogies used in 
classrooms (Lewthwaite et al., 2014). Beyond this tangible manifestation of the explicit curriculum was an aspiration for the curriculum (Eisner, 1979) to be epistemologically grounded in TH cultural values, a foundation identified as critical for First Nation student engagement in schools (Costagno \& Brayboy, 2008).

This consultation process resulted in a wide range of curriculum efforts, one being the development of a pedagogical framework for teaching and its application within newly developed curriculum resources, especially from grades 4 through 7 in science education (Lewthwaite et al., 2013, 2014). The second phase of the data collection, starting in 2009 and still ongoing, has involved providing support to teachers to implement the pedagogical framework and to investigate the effect, both qualitatively and quantitatively, of such actions upon student learning and engagement (Lewthwaite et al., 2014). Stakeholder commentary, especially from teachers, students, Elders and TH parents, on this process, through recorded interviews during and after these interventions, has been instrumental in gaining an understanding of processes, both at the individual teacher and the microsystem level.

Paralleling this initiative, starting in 2003 , have been a wide variety of formal perpetuating collaborative curriculum initiatives with a focus on providing the broad curriculum experience for students from kindergarten through grade 12 aspired to by the TH community, but still operating with the broadly defined mandated explicit curriculum defined by Yukon Education. Examples of these developments have included the Grade 10 Social Studies curriculum now focusing on TH culture and history. As well, TH citizens' traumatic experience with Residential School has been developed into an extensive curriculum component (Tr'ondëk Hwëch'in, 2010) of Grade 11 Social Studies. Further, language instruction in Hän, the TH language, has been offered since 2007 for students from kindergarten to grade 5. Additionally, traditional Culture Camps that focus on traditional rites of passage for TH youth have been developed by TH Heritage and actioned since 2008. These camps include First Hunt, Moose Camp, and First Fish, and are typically several days in length involving participation of Elders and parents as well as both $\mathrm{TH}$ and non-TH students. In the elementary grades, TH appointed Community Education Liaison Coordinators (CELCs) work with classroom teachers and TH staff and citizens to incorporate Traditional Knowledge through field trips which are either daily outings or overnight camps. In association with the initiation of these formal curriculum initiatives, have been scores of more informal, what might be regarded as more opportunistic, initiatives including Elder story-telling, community visits, special assemblies, and a variety of strategies to improve parent-child-school liaison. During these developments, over 40 recorded interviews have documented participants' comments on the curriculum changes and participant response to these changes.

Although the research on the broad curriculum changes and the influences of these changes has been under investigation since 2008, we engaged stakeholders in a final research stage in late 2014 in order to more 
broadly consider the curriculum changes that had occurred over the past seven years. This part of the research, conducted by the second author, involved extensive interviews with the stakeholders previously identified. In all, 15 interviews were conducted seeking stakeholder views on the changes that had occurred since self-governance, especially in regard to the curriculum experiences offered to students. The interviews were primarily unstructured conversations around two research questions: What processes have led to change in, or thwarted the realization of aspirations manifest in the SGA, and what tensions do you see with curriculum change as a result of a change in governance agreements? In all, the interviews averaged in length from 30 minutes to two hours. The conversations were transcribed and verified as accurate by the participants, who were also asked to adjust any aspects of the interviews in order to better illustrate the points they sought to convey. The transcriptions were then analyzed inductively around the focus of the research, especially around influences on change and tensions associated with change. This procedure corresponded with the analytical approach endorsed in empirical phenomenology which assumes that a structure exists in the shared experiences of a phenomenon. By so doing, the methodology would seek to reveal the structure of each commentary and its essential constituents (Moustakas, 1994).

\section{Results}

In this section we draw upon the data collected over the research phases and subsequent analyses to respond to the two research questions. We provide excerpts from just one interview, despite most participants' request for extended narratives (Lewthwaite et al., 2014). These excerpts correspond with each theme to provide evidence for such claims and provide attention to the underlying theoretical frames for this paper. We do not mention names or titles in order to preserve the anonymity of participants.

Research Question 1: What processes have influenced, negatively or positively, curriculum change in accordance with the tenor of the SGA?

Regarding the research question 1 , six themes were identified. First, the changes in curriculum are seen to be of significant consequence for students and the community's future and are attributable to identifiable multi-system influences. Although we have documented the evidence of change, especially in regards to teachers' teaching and the influence of this on student learning (Lewthwaite et al., 2013, 2014), stakeholders were able to identify influences on this change, most of which were attributable, primarily, to the proximal processes which were operative amongst stakeholders:

I think it also helps with the understanding between the community and the school because one of the challenges that the school system faces is 
that we are a system, we are a bureaucracy, we are an institution, and many people do not have fond memories of their time in institutions like school. So we need to be finding ways to open those doors, to open lines of communication, to be able to work better together. And I think that this has been the key to the strategies that we've been using that have helped - doing it as a community. We still have a long ways to go but I think it's helped to break down some of the barriers and that it has helped families to be more understanding and responsive to be able to work together for the best interests of the students.

Second, although the SGA has provided an impetus for change, it, in itself, has not created the change. Evident within the commentary was attention to the macrosystem influence of the existent and emergent political system as a contributor to development (Bronfenbrenner, 2005). This was voiced with reference to the explicit detail of the SGA, as well as the flexibility available through Yukon Education's explicit yet flexible curriculum requirements (Yukon First Nation Education Advisory Committee, 2008):

The SGA was set up to provide for the assumption of responsibility for schooling by $\mathrm{TH}$; that is, its own unique and self-managed school, education system, but they didn't want that. Instead they wanted a cogovernance model but the wording in the SGA using words like 'shall' negotiate was inserted to ensure the Government of Yukon was obligated to negotiate matters in regard to education. This authoritative language served to elevate the position of the First Nation's imperatives. As well, corresponding with the tenor of SGAs to work towards education practice, "culture-based education" has been more recently identified by YE (1990) and its Education Act as one of the foundational principles for school development in the Yukon. YE policy requires community schools to create, preserve, promote, and enhance their culture, including arts, heritage and language in classrooms. The flexibility with curriculum allows for this.

Third, the changes that have occurred have occurred primarily because of a desire for change, primarily as a response to awareness of the need for change rather than legislated imperatives. Dominating the commentary was the identification of a "climate of readiness" (Fullan, 1993) derived primarily from a conscious awareness of the need for change of existing authoritarian tendencies, and acknowledgment that this knowledge was a foundation for taking constructive action (Bishop, 2003; Giroux, 2010). An interviewee states:

This power did not translate into immediate responsibility. There was an imperative for change, but that did not make it happen. It had to be an internal thing. A personal thing for those involved. We have offered programs before they were even sanctioned. [Now the inclusion of the Residential School experience is a national priority] but even before that we were doing it because our community wanted it to happen. The energy and pride that was evident within the SGA provided that foundation we 
needed for moving towards governance. It provided the momentum we required. It had to change and this opened the door for change.

Fourth, the changes have involved considerable serendipity, especially in regards to the coming together of capabilities. Bronfenbrenner (1979) refers to the importance of time and people as central influences on development. Change in time of the individual and the group but also the conditions within the environment, which the group operated provided a salutary effect on development. An interviewee explained the situation:

Soon after the SGA was signed there were some wanting immediate change and demanded it. That was not productive. We did not have the capability or capacity to make those changes. It rested on having the right personnel to bring this about. I think we have had a 'perfect storm' of events. We have a large capacity at the First Nation, with people that have the capability to work towards such change. Much of what has happened has occurred because of people who have had a long-term commitment to the town and have the skills and knowledge to contribute to change. There are strong relationships between $\mathrm{TH}$ and other community members. Many people who live here see a very positive future, built on that collaboration.

Fifth, the changes have been facilitated especially by the counsel of Elders guided by the tenets of the SGA for the reinstatement of traditional operative protocols. Commentary indicated that the process of development needed not only collaboration but also guidance. The social role of and interpersonal relationships with Elders (Bronfenbrenner, 2005) was seen as a significant influence on the developmental trajectory of curriculum, in all aspects. As outlined in the SGA, It was their role and relationship that invited and permitted more complex interaction with in curriculum (Bronfenbrenner, 1979). The Elder's involvement was explained clearly in an interview:

It has to be cautious. I have been told several times what I have done in my role with TH has been 'no good'. One of the big changes with the SGA is that our Elders now can serve as Elder, and we are growing to learn that relying on them for advice is absolutely vital. We seek that advice, we need that advice. If you don't do it right, you'll be told, but you'll also be helped to do it better next time.

Sixth, the changes that have occurred for this community are not identified as possible for all communities. Participants commonly referred to how curriculum development was not only time, people and process dependent; it was also context dependent (Bronfenbrenner, 2005):

Although other Yukon communities are negotiating similar conditions in their SGAs, I am not convinced it is all possible. Our community has a stable population and many people [from outside the Yukon] want to build a life here, for their family. It draws many special people and many $\mathrm{TH}$ citizens have increasingly stronger educational backgrounds and what to 
serve and lead. Having that resource base is not as common in other communities.

Apparent within these themes is evidence of the influences on curriculum development, in its broadest sense, in a Yukon FN, subsequent to the inception of a SGA. Clearly evident, as Bronfenbrenner (2005) asserts, is the influence of process, people, time and context on development. Similarly, a critical awareness of the perpetuating injustice of the existing social order and the possibility associated with SGA inception were identified as critical ingredients promoting curriculum development.

\section{Research Question 2: What tensions exist as a result of a change in governance agreements in regards to curriculum change?}

Regarding the research question 2, four themes were discovered. First, the curriculum development that has occurred and is occurring is not palatable to all. Evident within the commentary was evidence of competing tensions, especially associated with the purpose of education:

I think we have lost sight of what's worth learning in our world today and increasingly, as a rural community, we have always been challenged by parents to ensure we don't let things [curriculum] be too focused on matters outside of pure academics. I'll hear a parent say, I'm sending my kid to [city] because they'll get a better education there. Better to them means more academics. I can't see that a young person's development can be gained by just more academics. I think our focus is moving to acknowledge the importance of making sense of our natural world and our place in it. But it's not what everyone wants.

This commentary presents a very thoughtful critique and a "consciousness" of the tensions associated with the curriculum currently being provided in their community. The commentator questions an orientation to education that is exclusively focused either on an academic rationalistic view of education (Eisner, 1979) or one, that as Kemmis (2012) suggests is, ultimately, about the formation of culturally-located persons who in turn become a part of the collectives of communities, societies and our shared world. This community (Lewthwaite et al., 2013) in the first phase of the study, identified that, historically, schooling interfered with education because the schools were suffocated by a dominating focus on curricula and assessments and students' achievement. Clearly, the commentaries above suggest seek close attention to a wellconceptualised prioritisation of both, but not at the expense of either.

Second, the curriculum development necessary has not drawn attention to the fundamental changes some have sought. It is not surprising that evident within the commentary was the suggestion that the fundamental, underpinning "hidden" curriculum of the school had, potentially, not been disrupted and, potentially, the underlying curriculum of the school remained, unconsciously or consciously, unadjusted. This was evident in two lines of commentary. As one 
might expect, some questioned whether a TH cultural epistemology was underpinning the curriculum development and, indeed, whether this was possible and even desirable. As suggested by Smith (1997), a stakeholder's personal epistemology frames how we think about different ideas and practices in education and is largely impervious to adjustment. An interviewee expresses this sentiment:

The changes are significant. But I wonder what is possible. Is just the activity of school [curriculum] enough? I don't think so. I think it has to be much deeper and consistent with what we $[\mathrm{TH}]$ see as of value and hold important. I don't think we can expect that of a school and teachers unless they have that intimate knowledge and appreciation themselves.

Further commentary drew attention to perceptions of $\mathrm{TH}$ citizens, not $\mathrm{TH}$ culture, still grounded in deficit-theorizing. Despite the positive developments in curriculum at the broadest level drawing primarily from the perceived asset of $\mathrm{TH}$ culture as a fund of knowledge (González, Moll, \& Amanti, 2005), apparent in the conversations, especially from those of a critical awareness of such theorizing, were comments associated with teachers' perpetuating beliefs which would likely manifest itself in practice, especially in classroom interactions and perceived views of learners. As Shields, Bishop, and Mazawi (2005) assert, at the heart of many school systems' thinking is a belief or, at least, an assumption that Western ways are superior and that Aboriginal culture and specifically students may bring deficits to classrooms, not assets. Deficit thinking or theorizing, as it is called, is the notion that students, especially minority students, fail in school because they and their families experience deficiencies such as limited intelligence or behaviours that obstruct learning (Castagno and Brayboy, 2008; Valencia, 1997). The following interviewee questions if deficit thinking still persists:

I feel we have come a long way. But I wonder about what comes out the other end and who comes out the other end [upon graduation or in leaving school]. There is a lot of activity but has it really changed? I am not sure that what we [as TH citizens] see and seek is what everyone else sees and seeks. I think there can still be prejudice.

Third, the effect of such change has yet to be realized in areas that are seen as important indicators for success. The initial phase of the research exposed the aspiration of the FN to see students walking confidently and capably in "both" worlds (Lewthwaite et al., 2013, 2014). One of the imperatives in the initial phase of the research was towards such ends, but yet privileging academic foundations that were seen as the capital for future developmental success of both the individual and the FN:

Ultimately, we need to see higher graduation rates, especially students leaving with strong academic qualifications and strong in literacy and numeracy. The numbers [of TH citizens] graduating are increasing, but I am not convinced the [academic] quality of the background has improved.

Fourth, the practice and priority of teaching still situates teachers as authority. Evident within the commentary, and extending from point one above, 
was the apparent perceived positioning of teachers as authority, able to decide on, as indicated in the introduction to this paper, the what, how and why of education. Ultimately, teacher practice was corresponded to their professional beliefs (Pajares, 1992). As Alcoff (1988) suggests, positionality describes one's own social position in relation to the people one is working with. Commentary provided evidence that the perception was that not all teachers position themselves overtly as collaborators working with the FN towards the SGA intent. This is evident in the commentary below:

There has to be a getting away from a certain kind of content and a certain way of getting the content across. There has to be that consideration that things can be different and the First Nation can help teachers to tap into alternative approaches. But they have to be open to it. The emphasis on university preparation really confines how [some] teacher's teach and what you teach. They don't know any different. And it might be for just one student [in the class who might be going to university], but they still think that is the priority.

Overall, apparent within each of these tensions is a concern with the explicit and implicit intention of schools in a community seeking fulfilment of aspirations embedded with the tenets of a SGA and the orthodoxy of practice that has characterised the community's colonial history. Ultimately, what will be the re-definition of curriculum? The commentary indicates that such redefinition is successfully being operationalised, largely at the what and how level. Evidence indicates that there is, despite the significant development, a perpetuating "conscientisation," as a necessary foundation for constructive action for improving the curriculum experience for all students. It is apparent that at the why level the philosophical reason for education and the purpose of schooling is still being outworked, primarily due to the resolute attention to this imperative by several stakeholders. As Freire (1998) asserts, "They must perceive the reality critically... and this must become the motivating force for liberating action" ( $p$. 34).

\section{Discussion and Implications}

A variety of factors have contributed to the significant and relatively unproblematic curriculum development that has occurred within this community school since the SGA inception. Notable are the factors of people, process, context and time (Bronfenbrenner, 2005). Also evident, and likely most important, underscoring these four factors are the dynamics of these processes that have most significantly contributed to influencing the development; that is, the increasingly more complex manifestation of curriculum as expressed in the experiences provided for students, both $\mathrm{TH}$ and non-TH. As evidenced in the commentary, central to the development has been the proximal processes, those patterns of activation that drive stability and change. Critical to the development have been the constructive dispositions and collaborative relationships 
necessary to engage in curriculum development towards a shared purpose. It is this dynamic that ultimately provided for increasingly more complex interactions and, consequently, development along the curriculum aspiration trajectory.

Despite the efficacy of Bronfenbrenner's (2005) model in understanding the influences on change, the model fails to give attention to the significant driving force that causes change reflectively and critically towards the aspirations of the FN, embedded within the tenets of the SGA. As stated by Wood and Lewthwaite (2008), a critical and conscious awareness of perpetuating parameters of control on the developing social order of curriculum has been necessary as a transformative vehicle for working towards resolving issues of domination and marginalization (Lewthwaite \& McMillan, 2010). Although progress has been made in this area, commentary suggests such parameters, to some extent, still exist. As asserted by a key stakeholder:

I think that for everybody who's in education, the number one thing is to develop and establish relationships and build them. And I think it's especially valuable when you're moving to a new community and working in a community where you are expected to work towards community goals [not your goals but the community's goals]. And I think any educator who's coming to a new community, needs to be honest and vulnerable and say "I don't have all the answers." I would remind any new teachers to build the relations, make connections, and that would be not only the students, but also the parents and the greater community, and look for what is wanted and use the [human and physical] resources in the community to work towards these goals collectively, not on your own.

For this school community, exposure of and dialogue around some of the tensions is vital for working towards the achievement of aspirations identified through the multiple and ongoing phases of this study and embedded within the SGA. In drawing from other community-based curriculum developments in Indigenous settings (Lewthwaite \& McMillan, 2010), these tensions are not seen by the authors as negatives. As Freire (1998) asserts, there must be an authentic form of thought and action which is fundamental to the transformation of the neocolonial condition. This critical consciousness is seen as the impetus for ongoing and more significant dialogue for the school community. This awareness allows for a re-negotiating of the future which provides a basis for First Nation selfgovernance of education that accommodates and minimizes tensions and conflicts (Schouls, 2004). As stated by one Elder:

In our culture there is nothing more important than the learning that makes a person wise. The main thing the southern culture wants from school is 'head knowledge'. That is what it has always emphasized. I do not know why. It intrigues me.I think about what school would look like if we had worked together from the beginning to make the learning better for our younger ones. I look to the future in believing it will be more on our terms where both worlds can be combined. It will be not just about knowledge, but how to behave and be wise, not just knowing. This is what is happening now, but we have a long way to go. 
As suggested by Fallon and Paquette (2012) curriculum development is not a question of simply replacing an existing competing epistemology. Epistemologies are not easily replaced because they are grounded in participant beliefs (Pajares, 1992) and, as such, will remain both viable and visible and, thus, open to critique and contestation. This draws attention to the importance of cooperation and collaboration in governance and, as evidenced in this case, curriculum development. The question remains: Is the way this school community has negotiated the space between intended curriculum and enacted curriculum since SGA inception adequate for the future, recognising that the space is still occupied by tensions, primarily grounded in differences most significantly at an epistemological level.

\section{Conclusion}

Within the context of a Yukon First Nation's first decade of selfgovernance, this article has explored the processes influencing, mainly positively, curriculum development; that is, the broad learning experience provided for its FN citizens and the citizens of the broader community in the decade after transition to SGA. It has also explored the tensions that exist as a result of a change in governance agreements in regards to curriculum development. Curriculum development, in this study's case, has shown the centrality of SGAs and the Yukon Education Act in providing an environment and impetus for sanctioned change. It has also illustrated the importance of centrally-defined explicit curriculum imperatives being flexible enough for negotiation at the community and, ultimately, classroom level. It has, above all, identified the significance of collaborative and active engagement and human resource utilisation as pivotal to curriculum development. This documented exploration becomes important for other First Nations as they also seek to work towards curriculum deconstruction and construction based upon their cultural terms (Truth and Reconciliation Commission of Canada, 2015).

Finally, it has identified the reality of the tensions that exist when the intentions for curriculum enacted are drawn from our personal histories, both the colonised and the coloniser. The intentions of curricula, both overt and covert, have historically not adequately been grounded in the priorities of Indigenous communities because curricula are largely expressions of the dominant culture (Battiste \& Henderson, 2000). Upsetting this dominance is problematic, especially when there is a lack of critical awareness. The advent of SGAs for this FN indicate that the tenets of the SGA are not perceived, thus far, by stakeholders to represent a form of neo-colonialism; instead, SGAs are providing evidence of being a vehicle for facilitating decolonization (Fallon \& Paquette, 2012). Despite this promise of possibility for curriculum, there is evidence of a critical awareness, at least among some stakeholders, of a form of neocolonialism which ultimately may prevent some of the fundamental epistemological considerations (McCue, 2004) for TH education from being 
actualised. This consciousness provides the impetus for recognising and negotiating the tensioned space, a space that has been pivotal to the successes achieved over the past decade and in which the promise of doing so for the decades ahead abides. Without entering into this tensioned space, TH will be unlikely to see the full realisation of their aspirations.

\section{Note}

1. This manuscript is based on the presentation given in the 2015 American Educational Research Association Annual meeting. The original presentation is available online from http://aut.researchqateway.ac.nz/bitstream/handle/ 10292/9035/Lewthwaite\%20et\%20al\%20(2015)\%20AERA\%20conference\%2 Opaper.pdf?sequence=2.

\section{References}

Alcoff, L. (1988). Cultural feminism versus poststructuralism: The identity crisis in feminist theory. Signs, 13(3), 405-36.

Battiste, M., \& Henderson, J.Y. (2000). Protecting indigenous knowledge and heritage: A global challenge. Saskatoon, SK: Purich.

Bishop, R. (2003). Changing power relations in education: Kaupapa Maori messages for 'mainstream' education in Aotearoal New Zealand. Comparative Education, 39(2), 221-238.

Bronfenbrenner, U. (1979). The ecology of human development. Cambridge, MA: Harvard University Press.

Bronfenbrenner, U. (1989). Ecological systems theory. In R. Vasta (Ed.), Six theories of child development: Revised formulations and current issues (pp. 187-249). Greenwich, CT: JAI Press.

Bronfenbrenner, U. (2005). Making human beings human: Bioecological perspectives on human development. London, UK: Sage.

Castagno, A., \& Brayboy, B. M. (2008). Culturally responsive schooling for Indigenous youth: A review of the literature. Review of Educational Research, 78(4), 941-993.

Creswell, J. W. (2012). Qualitative inquiry and research design: Choosing among the five traditions (3rd ed.). Thousand Oaks, CA: Sage.

Eisner, E. (1979). The educational imagination: On the design and evaluation of school programs $\left(2^{\text {nd }}\right.$ ed.). New York, NY: MacMillan. 
Fallon, G., \& Paquette, J. (2012). A critical analysis of self-governnace agreements addressing First Nations control of education in Canada. Canadian Journal of Educational Administration and Policy, 132, 1-28.

Foster, R. Y., \& Goddard, J. T. (2001). Leadership and culture in Northern Canada: Emergent themes and questions. International Electronic Journal for Leadership in Learning, 5(16), 1-13.

Freire, P. (1970). Pedagogy of the oppressed. New York, NY: Herder and Herder.

Freire, P. (1998). Pedagogy of freedom: Ethics, democracy, and civic courage. Lanham, MD: Rowman \& Littlefield.

Fullan, M. (1993). Change forces: Probing the depths of educational reform. London, UK: Falmer Press.

Giroux, H. (2010) Lessons from Paulo Freire. Chronicle of Higher Education, 57(9), B15-B16. Retrieved from http://chronicle.com/article/Lessons-FromPaulo-Freire/124910/

González, N., Moll, L., \& Amanti, C. (2005). Funds of knowledge: Theorizing practices in households, communities and classrooms. Mahwah, NJ: Erlbaum.

Gramsci, A. (1971). Selections from the prison notebooks. London, UK: International Publishers.

Kemmis, S. (2012). Contemporary schooling and the struggle for education. Bob Meyenn Lecture. Charles Sturt University. Albury, April 24, 2012. Retrieved from http://news.csu.edu.au/latest-news/society/the-strugglesfor-modern-education

Lewthwaite, B., \& McMillan, B. (2007). Combining the views of both worlds: Perceived constraints and contributors to achieving aspirations for science education in Qikitani. Canadian Journal of Science, Mathematics and Technology Education, 7(4). 355-376.

Lewthwaite, B., \& McMillan, B. (2010) "She can bother me, and that's because she cares": What Inuit students say about teaching and their learning. Canadian Journal of Education, 33(1), 140-176.

Lewthwaite, B., McMillan, B., Renaud, R., Hainnu, R., \& MacDonald, C. (2010). Combining the views of "Both Worlds": Science education in Nunavut piqusiit tamainik katisugit. Canadian Journal of Educational Administration and Policy, 98, 1-71.

Lewthwaite, B., Owen, T., Doiron, A., McMillan, B., \& Renaud, R. (2013). Our stories about teaching and learning: A pedagogy of consequences for Yukon First Nation settings. Interchange, 44(1-2), 105-128.

Lewthwaite, B., Owen, T., Doiron, A., Renaud, R., \& McMillan, B. (2014). Culturally responsive teaching in Yukon First Nations settings: What does 
it look like and what is its influence? Canadian Journal of Educational Administration and Policy, 155, 1-34.

McCue, H. (2004). An overview of federal and provincial policy trends in FirstNations education. In Chiefs-In-Assembly (Ed.), The new agenda: $A$ manifesto for First Nations education in Ontario. Toronto, ON: Chiefs of Ontario.

McKinley, E. (2000). Research and Maori education. In G. Haisman (Ed.), Exploring issues in science education (pp. 24-35). Wellington, NZ: Research and Curriculum Division, Ministry of Education.

Moustakas, C. (1994). Phenomenological research methods. Thousand Oaks, CA: Sage.

Nguyen, P-M.; Elliott, J.; Terlouw, C. \& Pilot, A. (2009). Neocolonialsim in education: Copperative learning in an Asian context. Comparative Education, 45(1), 109-130.

Ornstein A. C., \& Hunkins, F.P. (2013). Curriculum foundations, principles and issues (6th ed). Boston, MA: Allyn and Bacon.

Pajares, M. F. (1992). Teachers' beliefs and educational research: Cleaning up a messy construct. Review of Educational Research, 62(3), 307-333.

Schouls, T. (2004). Shifting boundaries: Aboriginal identity, pluralist theory and the politics of self-government. Vancouver, BC: UBC Press.

Shields, C., Bishop, R., \& Mazawi, A. (2005). Pathologizing practices: The effect of deficit thinking on education. New York, NY: Peter Lang.

Sjoberg, G., Williams, N.,Vaughan, T., \& Sjoberg, A. (1991). The case study approach in social research. In Feagin, J., Orum, A., \& Sjoberg, G. (Eds.), A case for case study (pp. 27-79). Chapel Hill, NC: University of North Carolina Press.

Smith, G. H. (1997). The development of Kaupapa Maöri theory and praxis. Auckland, NZ: Department of Education, University of Auckland.

Tr'ondëk Hwëch'in (1998). Tr'ondëk Hwëch'in Self-Governing Agreement: Dawson City, Yukon: Authors.

Tr'ondëk Hwëch'in (2010). Tr'ëhuhch'in Näwtr'udäha/Finding our way home. Dawson City, Yukon: Authors.

Truth and Reconciliation Commission of Canada (2015). Truth and Reconciliation Commission of Canada: Calls to action. Winnipeg, MB: Authors.

Valencia, R. (Ed.). (1997). The evolution of deficit thinking: Educational thought and practice. New York, NY: Routledge.

Wood, A., \& Lewthwaite, B. E. (2008). He putea whakarawe: Māori science education in Aotearoa New Zealand. Cultural Studies of Science Education, 3(3), 625-662. 
Yukon Bureau of Statistics (September, 2014): "Population report". Retrieved from http://www.eco.gov.yk.ca/stats/pdf/populationSep 2014.pdf

Yukon Government (1990). Education Act. Whitehorse, YT: Author.

Yukon First Nations Advisory Council. (2008). Helping students succeed: Vision, goals, and priorities. Whitehorse, YT: Author.

\section{Author Contact}

Brian Ellis Lewthwaite: brian.lewthwaite@jcu.edu.au

James Cook University, 1 James Cook Dr, Townsville City QLD 4811, Australia

Thomas Owen: thomas.owen@aut.ac.nz

School of Communication Studies, Auckland University of Technology, Private

Bag 92006, Auckland 1142, New Zealand

Ashley Doiron: Ashley.Doiron@trondek.ca

Tr'ondëk Hwëch'in First Nation, Yukon Territory, Dawson City, Yukon, Y0B1G0, Canada 